\title{
Subvertendo o desejo no teatro das organizações: problematizações contemporâneas sobre o desejo e a expansão da vida nas relações de trabalho'
}

\author{
Subverting the desire in the theatre of organizations: contemporary concerning about \\ desire and expansion of life in the labor relations
}

Eloisio Moulin de Souza ${ }^{2}$
Mônica de Fátima Bianco

\section{Resumo}

Este artigo pretende problematizar a concepção de desejo contida nas abordagens estruturalistas e pós-estruturalistas, colocando o desejo como objeto fundamental da análise contemporânea das relações de poder no local de trabalho, enfatizando a incapacidade do conceito estruturalista de desejo no processo de construção e catalisação de espaços laborais que promovam a expansão da vida. . Para tanto se realizou uma pesquisa qualitativa fundamentada na análise bibliográfica sobre o desejo, focando-se em Freud e no estruturalismo de Lacan, bem como no pós-estruturalismo de Deleuze, Rolnik e Foucault, salientando-se que este artigo adota uma concepção pós-estruturalista de desejo. Concluise que as teorias psicanalíticas modernas (Freud), estruturalistas (Lacan), bem como os trabalhos organizacionais de Chanlat e Dejours que utilizam a psicanálise em suas análises, ao definirem o que é desejo acabam criando fatores inibidores e despotencializadores do processo ético-político-estético de expansão da vida no local de trabalho. Diferentemente, o pós-estruturalismo, ao definir o desejo como social, capaz de construir e desconstruir realidades, consegue potencializar e problematizar a complexidade que envolve a expansão da vida no trabalho e na sociedade contemporânea.

Palavras-chave: desejo; poder; pós-estruturalismo; expansão da vida; trabalho.

\section{Abstract}

This article aims to discuss the conception of desire contained in structuralist and post-structuralist approaches, putting the desire as fundamental object of contemporary analysis of power relations in the workplace, emphasizing the inability of the structuralist concept of desire in the construction process and to catalyze the expansion of life in workplace. This

Artigo submetido em maio de 2010 e aceito para publicação em abril de 2011.

1 Uma versão preliminar deste trabalho foi apresentada no evento XI Colóquio Internacional sobre Poder Local promovido pelo Centro Interdisciplinar de Desenvolvimento e Gestão Social (CIAGS) e Núcleo de Pós Graduação em Administração (NPGA), sediados na Escola de Administração da UFBA, Salvador/Bahia no período de 14 a 16 de dezembro de 2009.

2 Doutor em Psicologia; Professor Adjunto do Departamento de Administração UFES. Endereço: Av. Fernando Ferrari, 514, Goiabeiras, Vitória, ES, Brasil, CEP 29075-910. E-mail: eloisiomoulin@gmail.com

${ }^{3}$ Doutora em Engenharia da Produção; Professora Associada do Departamento de Administração UFES. Endereço: Av. Fernando Ferrari, 514, Goiabeiras, Vitória, ES, Brasil, CEP 29075-910. E-mail: mfbianco@ig.com.br 
search was grounded on bibliography analysis of the literature about desire, based on Freud's and Lacan's structuralism and Deleuze's, Foucault's and Rolnik's post-structuralism. This article adopts a post-structuralist concept of desire. It concludes that modern psychoanalyze theory (Freud), structuralism (Lacan), as well the organizational work of Chanlat and Dejours that use psychoanalysis in their analysis to define what is desire contribute to create inhibiting factors and unpowerment the ethical-political-esthetic process of expansion of life in the workplace. In contrast, post-structuralism that defines desire as social and capable of constructing and deconstructing realities can empower and discuss the complexity that involved the expansion of life at work and in contemporary society.

Keywords: desire; power; post-structuralism; expansion of life; work.

\section{Introdução}

A concepção de desejo não é algo estável e fixo, modificando-se de acordo com os períodos históricos. Não é de hoje que os diversos ramos das ciências sociais têm se debatido sobre questões relativas à modernidade e a pós-modernidade. Nas últimas décadas, alguns autores organizacionais começaram a incluir esse debate em seus estudos, onde se destacam os trabalhos de Vieira e Caldas (2007), Alvesson e Deetz (1998), Cooper e Burrell (2007), Parker (1995) e Hatch (1997).

Vieira e Caldas (2007) apontam que a partir dos anos 80 têm surgido vertentes de resistência à hegemonia funcionalista nos estudos organizacionais. Dentre essas vertentes, os autores salientam os estudos interpretacionistas, a teoria crítica das organizações e as abordagens pós-modernas. Contudo, para eles existem diferenças significativas entre essas abordagens e, por si só, o fato de representarem vertentes que atuam como resistências às práticas funcionalistas de pesquisa, não confere a elas uma unicidade ou similaridade.

Alvesson e Deetz (1998) também salientam as diferenças entre a teoria crítica e as abordagens pósmodernas. Para eles, o principal ponto que afasta a teoria crítica das abordagens pós-modernas é o grau de envolvimento de cada uma delas com o projeto da modernidade. Os autores afirmam que a teoria crítica não pretende abandonar o projeto da modernidade, mas sim reformá-lo, mantendo-se com relação ao projeto da modernidade o que consideram positivo e reformulando suas características negativas. Já a pós-modernidade, para Alvesson e Deetz (1998), não deposita mais nenhuma fé ou esperança no projeto da modernidade e em função disso defende toda a sua extinção, pois para a pós-modernidade todo o projeto da modernidade está errado e deve ser inteiramente abandonado e sepultado.

Cooper e Burrell (2007) fazem uma análise comparativa entre obras consideradas por eles modernas e pósmodernas, para tanto consideram modernas as obras de Bell, Luhmann e Habermas, e pós-modernas as de Nietzsche, Foucault, Derrida e Lyotard. Hatch (1997) escreve um livro sobre Teoria Organizacional (TO) tentando demonstrar aspectos modernos, simbólicos e pós-modernos presentes nos estudos organizacionais. Parker (1995) faz uma crítica ao movimento pós-moderno contido nos estudos organizacionais; ironizando principalmente a descrença que o pós-modernismo tem em relação aos ideais de progresso e verdade contidos na ciência moderna. Vale ressaltar que os estudos organizacionais que utilizam abordagens psicanalíticas freudianas e lacanianas também se encontram inseridos no movimento de ruptura com práticas funcionalistas hegemônicas.

Com relação ao uso do termo pós-modernidade nas obras citadas, como será explicado posteriormente, acredita-se que, em alguns momentos, há um equívoco referente ao uso do mesmo pelos autores. Aliás, esse equívoco está presente em Vieira e Caldas (2007), Cooper e Burrell (2007), Hatch (1997), Alvesson e Deetz (1998) e Parker (1995). A palavra pós-modernidade é empregada por esses autores como significando uma abordagem de pesquisa, uma corrente teórica, o que no entender desse trabalho não o é. 
Uma das problemáticas aqui desenvolvidas enfatiza que pós-estruturalismo não é sinônimo de pósmodernismo como parecem acreditar Cooper e Burrell (2007), Vieira e Caldas (2007), Alvesson e Willmott (1996) e Alvesson e Deetz (1998) em seus trabalhos. Por exemplo, esses autores classificam os trabalhos de Foucault (1984, 1985 e 1988) e Derrida (2004) como sendo formas de abordagem pós-modernas ou pertencentes à Teoria Crítica. Apesar de Parker (1995) considerar o pós-modernismo uma corrente teórica de pesquisa, o autor parece ser mais coerente que os anteriormente citados, pois não considera Foucault e Derrida pós-modernos, mas sim pós-estruturalistas. Entretanto, os autores desse artigo reconhecem que qualquer tentativa de classificação de pensadores tão complexos, como Foucault e Derrida é algo que sempre estará sujeito a reinterpretações, aliás, qualquer classificação já é por si só uma relação de poder. Entretanto, autores como Foucault e Derrida serão tratados nesse artigo de forma semelhante ao definido por Parker (1995), ou seja, como representantes do pós-estruturalismo.

Em função do exposto e dentro do debate que envolve as abordagens científicas modernas, estruturalistas e pós-estruturalistas, esse artigo objetiva problematizar o conceito de desejo contido no estruturalismo e pósestruturalismo, evidenciando a incapacidade das abordagens estruturalistas de atuarem como catalisadoras dos processos relacionados à expansão da vida dos trabalhadores dentro do contexto organizacional contemporâneo. Expansão da vida é definida como um princípio que ao mesmo tempo é um antiprincípio. Ou seja, é um princípio que torna obrigatória uma constante mudança de princípios. A expansão da vida é algo vital e não moral, pois é "sempre em nome da vida, e de sua defesa, que se inventam estratégias, por mais estapafúrdias" (ROLNIK, 1989, p. 70). Assim sendo, esse princípio "nunca esquece que há um limite do quanto se suporta, a cada momento, a intimidade com o finito ilimitado, base de seu critério: um limite de tolerância para a desorientação dos afetos, um "limiar de desterritorialização"” (ROLNICK, 1989, p. 70). Por fim, o princípio de expansão da vida "sempre avalia o quanto as defesas que estão sendo usadas servem ou não para proteger a vida" (ROLNICK, 1989, p. 70).

Defende-se aqui que o pós-estruturalismo, por meio de seu conceito sobre desejo, possui um maior potencial expansionista da vida, o que lhe proporciona atuar de forma mais efetiva em relação às práticas hegemônicas contemporâneas de poder, práticas essas relacionadas também ao dispositivo da sexualidade no local de trabalho. Portanto, para o pós-estruturalismo, a definição do que é desejo adquire um papel importante nesse processo de expansão da vida, não sendo visto aqui como algo secundário, mas sim como um dos pilares fundamentais de ordenação de toda sociedade e, consequentemente, um dos principais catalisadores de mudanças sociais, inclusive mudanças no trabalho.

Assim, esse artigo se constitui como uma pesquisa qualitativa de cunho bibliográfico. Ele está organizado da seguinte forma: inicialmente é apresentado o significado de modernidade e pós-modernidade, ambos entendidos como períodos sócio-históricos e não como abordagens de pesquisa ou correntes de pensamento. Em seguida, serão discutidas algumas influências recebidas por algumas teorias sociais pelo projeto da modernidade, como por exemplo o estruturalismo lacaniano e Freud, bem como o conceito de desejo dentro dessas perspectivas. Por fim, serão apresentados os principais aspectos do pós-estruturalismo que o legitimam como capaz de expandir a vida dentro do espaço organizacional por meio de sua concepção sobre o desejo.

\section{Significado de Modernidade e Pós-modernidade}

O que significa modernidade e pós-modernidade? Quais são suas relações com o pós-estruturalismo? Aliás, o que significa pós-estruturalismo? Pós-estruturalismo e pós-modernidade podem ser entendidos como sinônimos? Quais os principais conceitos sobre desejo defendidos na modernidade e na pós-modernidade? Os próximos tópicos deste artigo têm o intuito de trazer alguns esclarecimentos sobre essas questões. Nesse tópico pretende-se discutir o significado de modernidade e pós-modernidade. 
Modernidade é considerada nesse trabalho como um período histórico constituído por diversas formas hegemônicas de relações de poder. Essas relações de poder que emergem nesse período criam condições históricas, sociais, tecnológicas, econômicas, políticas e culturais, dentre outras, para o surgimento da ciência. Nesse processo o homem tenta se libertar dos dogmas da Igreja, buscando uma liberdade de criação que não estivesse baseada em sistemas teológicos (KIRST et al, 2003). Cooper e Burrell (2007) concordam com Kirst (2003), pois afirmam que a modernidade é o momento em que o homem se inventa, deixando de se ver como um reflexo de Deus ou da natureza. Assim, na modernidade aparecem diversos caminhos para se chegar à verdade sobre algo. Contudo, essa diversidade trouxe uma instabilidade e insegurança na busca da certeza e da verdade sobre as coisas (KIRST et al, 2003).

Nesse período histórico a concepção de ciência se fortalece e ganha corpo a partir do século XVIII, principalmente com a influência do Iluminismo no pensamento ocidental (COOPER; BURRELL, 2007). Alvesson e Deetz (1998, p. 231) salientam que o "Iluminismo prometeu um sujeito autônomo, progressivamente emancipado pelo conhecimento adquirido por meio dos métodos científicos. Notou-se o crescimento da razão sobre a autoridade e os valores tradicionais". Em concordância com Alvesson e Deetz (1998), Cooper e Burrell (2007, p. 313) salientam, a modernidade crê na "capacidade essencial da humanidade de buscar sua perfeição pelo poder de seu pensamento racional". Ocorre a clássica divisão entre sujeito/objeto e um modelo de ciência que privilegia o objeto em detrimento do sujeito. Nessa perspectiva, os fenômenos naturais passam a ser vistos como sendo ordenados e, consequentemente, seguindo a leis universais de funcionamento. Emerge, assim, o conceito e o modelo de ciência que dará traço à concepção da ciência na modernidade (ANDRADE, 1999). Dessa forma, dentro do contexto histórico moderno, o pesquisador passa a ter o papel de encontrar estas leis universais, para, dessa forma então, melhor conhecer e conseguir controlar os fenômenos pesquisados.

Portanto, inserido na modernidade, para que qualquer ramo do conhecimento tenha o status e título de ciência, o mesmo teria que estar sustentado na ordenação da natureza. Dessa forma, os saberes que se dedicam ao estudo do homem, influenciados pela concepção de ciência na modernidade e, preocupados em conseguir uma legitimação dentro da comunidade científica, passam a adotar essa concepção de ciência para analisar fenômenos relacionados ao homem, ou seja, o homem é equiparado a fenômenos naturais e seu estudo deve seguir os mesmos procedimentos aplicados no estudo da natureza para que tenham validade científica (SOUZA et al, 2006). Nesse sentido, Cooper e Burrell (2007) salientam que o modernismo acredita em um mundo intrinsecamente lógico que se constitui pela Razão e sólida fundamentação universal, onde o discurso reflete a razão e a ordem pré-existente que existe "lá fora" no mundo, bem como de que o homem é um agente pensante e autônomo, um sujeito que pode tomar consciência dessa ordem exterior. Esta forma cartesiana de se conceber a ciência traça um limite entre o mundo exterior e o mundo interior, fundamentando a neutralidade científica. Portanto, há uma correlação entre "o modernismo com o projeto do Iluminismo, isto é, o progresso ocorre pela aplicação da razão e o desenvolvimento social, pelos avanços na ciência e tecnologia" (MARSDEN; TOWLEY, 2001, p. 48).

Touraine (1998) também acredita que a modernidade é marcada pelo advento e sucesso da "razão". Para a modernidade, essa "razão" seria o agente capaz de provocar revoluções sociais e a emancipação do homem. O posicionamento de Touraine (1998) vai ao encontro de Weber (1999), onde a sociedade moderna é fundamentada no princípio racional-legal, no qual o predomínio da razão instrumental se torna o principal triunfo da modernidade. Contudo, para Weber (1999) o crescimento da razão instrumental não promove a realização da liberdade universal, mas sim a criação de uma racionalidade burocrática que atua como uma "gaiola de ferro" sobre o Homem. Harvey (2003) vai de encontro a Weber (1999) ao conceber a modernidade como sendo tecnocrata e racionalista. Segundo Harvey (2003) a modernidade está identificada com as seguintes crenças: progresso linear, existência de verdades absolutas, possibilidade de planejamento racional da ordem social ideal, padronização do conhecimento e da produção.

Entretanto, as ciências estão passando atualmente por um processo de autoanálise em que crenças anteriormente estimadas, dentre elas a crença na "razão" e no "progresso", passam por uma reflexão crítica 
(COOPER; BURRELL, 2007). Contudo, para Cooper e Burrell (2007), o modernismo e o pós-modernismo não são períodos históricos, mas são posições epistemológicas que polarizam esse debate na atualidade. Contrariamente a esta definição de modernidade e pós-modernidade defendida pelos autores, salienta-se aqui que o modernismo não é uma corrente de pensamento, mas um período histórico que tem influenciado diversas vertentes de ciência conforme salientado por Andrade (1999).. Apesar de não se poder afirmar que o estruturalismo é uma abordagem totalmente concebida dentro de uma lógica histórica moderna, conforme demonstrado por Souza (2010), há um traço no estruturalismo que o mantém com resquício moderno: a busca de leis universais de funcionamento.

Araújo (1993) afirma que a finalidade da pesquisa estruturalista é conhecer o que há de universal no ser humano que possa ser apreensível e cognoscível pela ciência. "A possibilidade de se fazer ciência, de se formalizar, ou seja, de encontrar as estruturas universais, inconscientes e invariantes caracteriza o método estruturalista" (ARAÚJO, 1993, p. 127), sejam essas estruturas representadas por leis universais ou pela busca de identidades. Aliás, Sawaia (2001) informa que a busca por identidade é o valor fundamental da modernidade. Toda generalização é uma busca de características que sejam comuns e que possibilitem encontrar uma identidade. Entretanto, para Sawaia (2001), toda identidade é um mecanismo de poder onde inclusão e exclusão operam de forma conjunta. Assim, para a autora, a identidade estabelece uma relação de poder onde as significações hegemônicas acabam excluindo as não-hegemônicas. Ao se estabelecer a diferença entre duas identidades, tende-se a incluir e valorizar o que é considerado hegemônico e a desvalorizar e excluir aquilo que é considerado minoria, com o principal intuito de preservar a harmonia social e evitar o conflito.

Entretanto, como nada é definitivo, acabado e natural, o modelo de ciência emergido na modernidade passa a sofrer várias críticas, inclusive algumas dessas críticas são levantadas pelo próprio estruturalismo. Essas críticas advêm, novamente, de um novo contexto social, histórico, político, econômico, tecnológico e cultural que fazem sair dos bastidores do teatro novas relações de poder. Esse período é denominado aqui como pósmodernidade. Portanto, esse artigo considera a pós-modernidade, também denominada de contemporaneidade, como momento social e histórico que tem como principal característica uma forte aceleração das mudanças sociais, provocando incertezas e fragmentações no solo das concepções modernas. Sarup (1996) defende que as transformações culturais da sociedade nas duas últimas décadas transformaramna. Esta transformação é denominada pelo autor de pós-modernidade. Para ele, a sociedade pós-moderna se caracteriza pela aceitação do efêmero, do fragmento e da descontinuidade. No campo científico, Sarup (1996) enfatiza o combate emergente na pós-modernidade às metanarrativas ou metateorias por meio das quais cada coisa existente no mundo poderia ser conectada ou representada pela ciência. Para o autor, há uma intensa desconfiança de todos os discursos globais e totalizantes, uma rejeição a metanarrativas, interpretações teóricas de larga escala e de aplicação universal. Ocorre uma condenação

das metanarrativas de Hegel, Marx e Freud como totalizantes. [...] Pós-modernos rejeitam a visão Hegeliana de história e a ideia de progresso; na filosofia há uma tendência, associada com o pós-estruturalismo e pós-modernismo, que qualquer projeto universal de emancipação humana é algo suspeito (SARUP, 1996, p. 95, tradução nossa).

Lyotard (1986) acredita que por volta dos anos 50 ocorrem modificações nos estatutos da ciência que culminam com o pós-moderno. Para ele, o fato mais importante dessas mudanças, originadas na crise da ciência e da verdade, não foi somente a substituição de uma concepção de ciência má por outra. O que ocorreu foi uma mudança na natureza da ciência, provocada principalmente pelas transformações tecnológicas sobre o saber. A ciência se afasta da metafísica com a pós-modernidade, com isso ela também se afasta de conceitos como razão, sujeito autônomo, identidade, totalidade, verdade e progresso. "O pósmoderno, enquanto condição da cultura nesta era, caracteriza-se exatamente pela incredulidade perante o metadiscurso filosófico-metafísico, com suas pretensões atemporais e universalizantes" (LYOTARD, 1986, p. VIII). 
Bauman (2001) salienta que esse cenário social de fragmentação e incerteza não é apenas um acontecimento momentâneo que estaria conduzindo a passagem da modernidade para a pós-modernidade. Fragmentação e incerteza são os principais traços da pós-modernidade e não são vistos aqui como características ou aspectos meramente transitórios. Da mesma forma que as relações da modernidade estabelecem o que deve ser considerado ciência, a pós-modernidade é um momento de mudanças sociais que provocam mudanças históricas e, consequentemente , o aparecimento de novas formas de pensar e conceber ciência (BAUMAN, 1998). Portanto, pode-se afirmar que pós-modernidade é, ao mesmo tempo, uma nova forma de sociedade (BAUMAN, 1998, 2001) que provoca mudanças históricas que acabam constituindo uma nova matriz epistemológica nas ciências (HASSARD, 1993). Já para Jameson (1985), pós-modernismo não é um estilo ou moda, mas uma cultura de dominação promovida pelo capitalismo tardio.

Uma questão fundamental para a pós-modernidade é o sujeito. No modernismo, conforme já salientado, o mundo é algo lógico, constituído pela razão e com uma fundamentação de universalidade. Assim, o discurso reflete a razão e a ordem que já estão prontas "lá fora" no mundo. Para que isso aconteça, há para a modernidade um agente pensante, um sujeito autônomo e consciente dessa ordem exterior (COOPER; BURRELL, 2007). Já o sujeito pós-moderno é visto como algo fragmentado, não-autônomo e sem uma identidade. Jameson (1985) coloca que uma das consequências da visão pós-moderna é que não se pode conceber o indivíduo como alienado, conforme acredita o marxismo clássico, pois para o indivíduo ser algo alienado, pressupõe-se um senso em que o indivíduo é algo coerente, ao invés de fragmentado. Dessa forma, para Jameson (1985), é somente em termos da existência de um senso centrado de identidade pessoal que a modernidade acredita que indivíduos podem assumir projetos para o futuro, ou pensar coerentemente sobre a produção de um futuro significativamente melhor do que o atual. De forma oposta, as correntes de pensamento que emergem na pós-modernidade, como por exemplo o pós-estruturalismo, a alienação do sujeito é substituída pela fragmentação do sujeito.

Concorda-se com Alvesson e Deetz (1998, p. 229) ao afirmarem que o "pós-modernismo é de muitas maneiras, muito mais difícil de ser delimitado. Nas ciências sociais, o termo tem sido usado para descrever um clima social, um período histórico caracterizado por mudanças sociais [...]”. O pós-modernismo denuncia o lado escuro do Iluminismo com suas exclusões orquestradas por meio de um discurso fundamentado na razão, na autonomia do homem e no progresso social. Esse discurso do Iluminismo, visto sob sua própria ótica, intenta produzir um discurso científico vestido de neutralidade e repleto de boas intenções para com a humanidade (ALVESSON; DEETZ, 1998).

Contudo, conforme enfatizado por Peters (2000), não se deve confundir pós-estruturalismo com pósmodernismo. Para o autor enquanto o pós-modernismo é uma época histórica o pós-estruturalismo é uma sistematização teórica que atua principalmente sobre a linguagem e processos de significação. Além disso, sendo uma época histórica, o pós-modernismo é algo muito mais amplo do que o pós-estruturalismo. Neste sentido Monteiro (1995, p. 41) já alertava que a pós-modernidade "está na literatura, na arte, na cultura, na ciência, na política. Provoca diferentes reações. Alguns buscam elaborar conceito consistente; outros buscam experimentá-la concretamente; outros ainda a vivem sem saber do que se trata. A pós-modernidade ultrapassa os limites da academia". Assim, pós-estruturalismo é um movimento acadêmico, uma epistemologia, enquanto a amplitude da pós-modernidade a torna um movimento histórico, social, cultural, e não somente acadêmico ou filosófico.

Peters (2000, p. 28) enfatiza que o pós-estruturalismo é caracterizado como uma forma de pensar, uma maneira de filosofar e escrever, muito embora não deva ser visto como uma ideia homogênea. Para o autor, pós-estruturalismo é um "rótulo utilizado na comunidade acadêmica de língua inglesa para descrever uma resposta distintivamente filosófica ao estruturalismo [...]" e ao Iluminismo.

Assim sendo, modernidade tem uma relação direta com pós-modernidade, enquanto que pós-estruturalismo está em relação direta com o estruturalismo. Embora pós-modernismo seja frequentemente confundido com pós-estruturalismo e sabendo-se que há " sobreposições filosóficas e históricas entre os dois movimentos, é 
importante distingui-los para que possamos avaliar suas respectivas genealogias, trajetórias e aplicações" (PETERS, 2000, p. 9), pois pós-modernismo e pós-estruturalismo têm objetos teóricos completamente diferentes. Nesse aspecto pode-se afirmar que o pós-estruturalismo toma como seu objeto de embate o estruturalismo, enquanto o pós-modernismo o modernismo. Dessa forma, pós-estruturalismo e estruturalismo representam transformações no campo do conhecimento, ou seja, epistemes, enquanto pósmodernismo e modernismo são momentos históricos (ontologias) (SOUZA, 2010). Portanto, uma vez discutido aspectos da modernidade, pós-modernidade, estruturalismo e pós-estruturalismo, será demonstrado em seguida as relações da modernidade com as obras de Lacan (1986, 1988, 1995) e Freud (1974a, 1974b, 1974c, 1974d), bem como, suas implicações sobre o desejo.

\section{Freud e Lacan: Desejo Metafísico, A-histórico e Transcendental}

Em sua maioria, as análises organizacionais sobre os processos de trabalho tendem a privilegiar aspectos sócioeconômicos, como, por exemplo, o conceito de classe social (PARKER, 2005). Aliás, generalizações e construções de conceitos identitários é uma característica da modernidade que está presente em diversas teorias, conforme anteriormente discutido. Esta busca identitária explica por que conceitos como classe e ideologia, dentre outros, são fundamentais para a Teoria Crítica, por exemplo (PARKER, 1999). Entretanto, as análises organizacionais relacionadas aos processos de trabalho acabam dando menor valor a aspectos relacionados ao desejo, gênero, idade e sexualidade, dentre outros, em seus estudos (PARKER, 2005).

Contudo, de forma até paradoxal, apesar de considerar os estudos que envolvem desejo, gênero e sexualidade como algo secundário em relação aos estudos voltados para a dominação econômica exercida pelo sistema capitalista de produção sobre os trabalhadores, tem ocorrido nas últimas décadas uma busca nos estudos organizacionais pelas abordagens psicanalíticas como forma de diminuição da opressão sobre essa classe. Como exemplo, podemos citar os trabalhos de Chanlat (1996a, 1996b) e Dejours (1992, 2001, 2003) que caminham nessa direção. Por que isso é algo paradoxal? Simplesmente porque, apesar das teorias psicanalíticas tentarem entender o homem por meio da ênfase a questões ligadas à sexualidade e ao desejo, estas questões são colocadas em segundo plano por Chanlat e Dejours. Assim, existe em Chanlat e Dejours uma influência muito grande dos conceitos de Freud e Lacan, sendo este último considerado um legítimo representante do pensamento estruturalista (DOSSE, 2007). Logo, há uma forte influência das concepções modernas e estruturalistas sobre o desejo nas obras de Freud e Lacan que, consequentemente, estão presentes também nos trabalhos de Chanlat e Dejours. Com este entendimento, esse artigo denomina as obras de Freud e Lacan de psicanálise modernista/estruturalista, para diferenciá-las de outras práticas psicanalistas, como, por exemplo, a esquizoanálise. Estas concepções modernistas/estruturalistas presentes em Freud e Lacan serão explicadas abaixo.

Para Freud (1974c), a existência de necessidades sexuais tanto no homem, como nos animais, se expressa na biologia exatamente pelo pressuposto da existência de uma pulsão sexual, da mesma forma que há para ele uma pulsão de nutrição: a fome. Assim, de forma equivalente à pulsão de nutrição, para Freud (1974c), a pulsão sexual é a libido. Contudo, nesse processo de satisfação da pulsão sexual ocorre um grande número de desvios em relação ao objeto sexual e ao alvo sexual (FREUD, 1974c). Mas o que seriam objeto e alvo sexual?

Objeto sexual é para Freud (1974c) a pessoa de quem a atração sexual provém, e alvo sexual é a ação para a qual a pulsão impele e caminha. Um dos desvios em relação ao objeto sexual é a inversão. Freud (1974c) acredita que o início do desenvolvimento da libido no homem, denominada por ele de fase da primazia genital, deve ser precedida por uma fase de organização pré-genital. Nessa fase pré-genital a vida sexual infantil é autoerótica, pois o seu objeto sexual encontra-se no próprio corpo, bem como as pulsões sexuais são totalmente desvinculadas e independentes entre si em sua ação para obtenção do prazer. Como 
organização pré-genital, Freud (1974c) denomina as organizações da vida sexual nas quais zonas genitais ainda não assumiram o seu papel preponderante. Assim, para Freud existem duas fases pré-genitais: oral e sádico-anal. Na fase oral, também denominada por Freud (1974c) de canibalesca, a atividade sexual ainda não se separou da nutrição e nem se diferencia de correntes opostas em seu interior, pois o objeto de uma atividade também o é da outra, sendo que o alvo sexual consiste na incorporação do objeto (seios da mãe) que posteriormente irá ter, sob a forma de identificação, um papel psíquico importante.

A fase sádico-anal ocorre na divisão de opostos, que, segundo Freud (1974b), irá perpassar por toda a vida sexual, mas estes ainda não podem ser chamados masculino e feminino, no entanto podem ser denominados ativo e passivo. A atividade é produzida pela pulsão de dominação por meio da musculatura do corpo. A passividade se faz valer pela mucosa erógena do intestino. Conjuntamente, outras pulsões parciais também atuam de maneira autoerótica. Entretanto, nessa fase já se torna possível demonstrar a polaridade sexual e o objeto alheio, faltando ainda ocorrer a organização e a subordinação à função reprodutora (FREUD, 1974c). Entretanto, posteriormente, na vida sexual do adulto, a obtenção de prazer fica a serviço da função reprodutora, sendo que as pulsões parciais ficam sob o primado de uma única zona erógena que permitirá a consecução do alvo sexual num objeto sexual alheio (FREUD, 1974c).

Conceitos como: castração, Édipo, Electra, recalcamento, sublimação, fixação, identificação, transferência, dentre outros, irão criar e constituir todo um jargão conceitual psicanalítico sobre esse processo. Em suma, o investimento da energia sexual (libido) Freud chamou de catexia, que tem sido entendida pelo autor como o próprio desejo. Catexia é o processo pelo qual a energia libidinal disponível na psique é vinculada ou investida na representação mental de uma pessoa, ideia ou coisa. A libido que foi catexizada perde sua mobilidade original e não pode mais se mover em direção a novos objetos. Está enraizada em qualquer parte da psique que a atraiu e a segurou. Para complementar Freud fala que o núcleo do inconsciente consiste em representantes instintuais que procuram descarregar sua catexia, ou seja, consiste em impulsos carregados de desejo (FREUD, 1974d).

Tanto Freud (1974a) quanto Lacan (1995) concebem o desejo como algo produzido por meio de uma relação de castração e, consequentemente, de uma relação de repressão com o mundo real. Para eles desejo é sinônimo de caos, constituindo-se como algo anárquico. A partir da década de cinquenta, Lacan (1986, 1988, 1995) irá fazer uma releitura da obra de Freud tendo como principal eixo de análise o estruturalismo. A utilização do estruturalismo na psicanálise lacaniana irá permitir que o complexo de Édipo seja universalizado, retirando-o de uma perspectiva sociológica para colocá-lo como algo que faz parte do ambiente, naturalizando-o como algo socialmente determinado. Assim, observa-se em Lacan (1986, 1988, 1995) uma forte influência da antropologia funcional e da antropologia estruturalista de Lévi-Strauss (1967).

Sales (2008) observa que a maneira como Lacan pensa a conformação do desejo na travessia do Édipo é algo indissociável da ideia de estrutura. O Édipo transforma-se em algo transcendental articulado dialeticamente por dois significantes: o Nome do Pai e o Falo. O pai de família passa a ocupar uma dimensão simbólica, configurando-se como uma Lei simbólica que caracteriza a instauração da necessidade de separação da mãe. O Nome do Pai constitui o Édipo, pois para Lacan “Édipo 'é' a universalidade da função simbólica, então ele pode ser descrito como 'esquema mínimo da experiência humana' que, como tal, descreve a constituição do posicionamento subjetivo diante do Outro [Pai]” (SALES, 2008, p. 213).

Para Lacan (1995), o inconsciente funciona sob uma lógica combinatória das estruturas simbólicas, sendo que o papel da psicanálise é encontrar os operadores que possibilitam essa lógica se atualizar em um sujeito. Para Lacan (1995), um bebê recém-nascido, sem condições de dominar a linguagem e dependente da vontade e sorte que um outro lhe destina, irá estabelecer vínculos pulsionais com a mãe sob um regime imaginário que não diferencia amor e ódio, em que a aplicação de um "eu" implica a anulação do "outro". Entretanto, esse "outro", considerado por Lacan (1995) o primeiro Outro, já está submetido à regulação simbólica prescritiva do desejo. Contudo, a própria mãe procura outros alvos em termos de libido que não se remetem á criança, criando com isso um processo de presença e ausência em relação ao bebê. Sobre esse aspecto Sales 
(2008) informa que o que aparece como símbolo desses outros alvos é o Falo, ou seja, o desejo da mãe é o desejo do Outro, imagem sexualmente possuidora daquilo que seu corpo não tem e que se eleva á categoria de significante, ou seja, da presença de seu desejo. Assim, sendo

[...] o desejo é resultante, no corpo, do fracasso da linguagem em traduzir uma referência à realidade, o falo representa sua não conformação a qualquer objeto e sua eterna remissão ao desejo do Outro, isto é, à própria Lei inconsciente decretada pela estrutura que torna o desejo indissociável do significante (SALES, 2008, p. 214).

Sendo a Lei simbólica algo que instaura um corte em relação ao imaginário e, o pai com sua presença e voz provoca um intervalo entre a mãe e a criança, acaba-se criando os elementos necessários para uma leitura estrutural da psicanálise, leitura esta, em que para Lacan (1995) o Édipo irá ocupar o papel de agente estruturante. O Nome do Pai transforma o Édipo em um mito que deve ser vivido, considerado universal por Lacan, pois tudo o que pertence à ordem humana tem que ser submetido a um processo inconsciente, do que significam e da forma como incidem no corpo todos os ganhos e as perdas resultantes do uso da linguagem (SALES, 2008).

Assim, para Lacan (1995) o desejo não é algo sempre relacionado a um objeto que tenha uma existência concreta. Sobre este aspecto Sales (2008) diz que o funcionamento da estrutura psicanalítica lacaniana abre um lugar para o Falo que, ao lado do Nome do Pai, irá preencher a função do valor simbólico zero, ou seja, o falo e o Nome do Pai respondem pela atualização simbólica na estrutura, pela existência da estrutura, situando-se no limite do campo da linguagem, ao mesmo tempo em que representam e operacionalizam o limite por ela própria imposto.

Apesar de Freud (1974a) e Lacan (1995) conceberem o desejo como algo anárquico e o verem como sinônimo de caos, os autores também o naturalizam e constroem identidades, bem como leis universais. Por exemplo, a existência de um modelo binário-identitário de sexualidade (homem/mulher, ativo/passivo) é algo naturalizado nas obras dos autores. As outras formas de expressão sexuais são vistas como desviantes para Freud e Lacan. Esse binarismo é um traço também presente na maioria dos estudos organizacionais sobre gênero (homem versus mulher; homossexuais versus heterossexuais) ou a outros aspectos da vida organizacional, tais como: classe social (proletariado versus burguesia) e dominação (dominantes versus dominados).

Chanlat (1996a, 1996b) e Dejours (2001, 2003), ao promoverem a discussão sobre o indivíduo na organização e o fator humano no trabalho, utilizam, em suas definições e perspectivas de análise do ambiente organizacional, conceitos psicanalíticos fortemente influenciados e fundamentados nas obras de Freud e Lacan. O homem freudiano/lacaniano com sua pulsão e castração estão manifestos e representados nos estudos de Chanlat e Dejours. Entretanto, uma questão surge: o que o pós-estruturalismo diverge dessas abordagens em sua concepção de desejo? O próximo tópico deste artigo pretende responder essa questão.

\section{Pós-estruturalismo: Desejo Imanente e (Trans)Formador de Mundos}

O discurso produtor de uma sexualidade binária presente na psicanálise modernista/estruturalista cria o mito de identidades. Assim, para sobreviverem, os sujeitos são obrigados a constituírem territórios existenciais procurando a todo tempo defender e resgatar uma identidade, uma essência. Para isso, utilizam a produção discursiva hegemônica como sinônima de território existencial, tentando se encaixarem dentro dessas identidades previamente estabelecidas para se sentirem aceitos, realimentando aquilo que se quer combater. Assim, 
[...] a 'identidade' atribuída a algum antigo território transformado em essência não só é um mito criado no momento mesmo de sua reivindicação como, o que é pior, esse mito alimenta exatamente uma hipótese: a identidade no fundo é um mito funcional desse sistema, mito de referência profundamente ancorado na subjetividade de todos (ROLNIK, 1989, p. 153).

No pós-estruturalismo observa-se uma fuga ao essencialismo e um combate à busca de uma característica marcante e universal que constitua uma identidade. Ao analisar essa questão em relação aos estudos feministas, Costa (1998, p. 68) afirma que a "oposição binária entre essencialismo/antiessencialismo organizando os outros dualismos nas teorias feministas - juntamente com seu correlato, identidade/diferença - estruturam em grande parte a polêmica entre o feminismo e pós-modernismo/pós-estruturalismo". Para o pós-estruturalismo não existe uma identidade feminina ou uma masculina, não há busca de uma essência do que seja ser homem ou mulher, pois o Homem, para o pós-estruturalismo, é atravessado por relações de poder e de discurso que o constituem como algo heterogêneo.

Costa (1998) afirma que, no pós-estruturalismo, há um deslocamento dos objetos às palavras e isso traz como principal consequência uma revalorização da esfera cultural. A autora ainda salienta que os fatores que contribuem para tal deslocamento e revalorização de aspectos culturais são: (a) uma crítica à concepção de que a consciência repousa na matéria e que, dessa maneira, as relações econômicas determinam todo o resto (crítica ao materialismo), (b) uma descrença na busca de origens e de uma explicação originária ou uma causa primeira que viria a explicar tudo o mais (crítica ao fundacionismo) e, por fim, (c) uma renovação ao caráter construtivo da linguagem.

Acredita-se, no pós-estruturalismo, que os discursos constroem subjetividades e organizam as relações de poder e de resistência, definindo o que deverá ser considerado verdade e realidade (FOUCAULT, 1996, 2003). Entretanto, conforme Costa (1998) mesmo salienta, pode-se considerar o discurso não apenas como determinante (visão estruturalista), mas também, ao mesmo tempo, como determinado por diversos fatores sociais, tais como o imperialismo, a sociedade patriarcal, o racismo, a discriminação sexual, o capitalismo e a globalização. Como Foucault (1996, p.30-31) mesmo afirma, o importante em uma análise do discurso é "saber quais as condições impostas a um sujeito qualquer para que ele possa se introduzir, funcionar, servir de nó na rede sistemática do que nos rodeia”. Assim, Foucault (1996, 2003), como representante do pósestruturalismo, não acredita em um sujeito cognoscente e autônomo, consequentemente, não acredita em um sujeito criador de discurso. Assim, os sujeitos se limitam a entrar na análise do discurso, "por portas por assim dizer laterais, no interior de um sistema, que não somente se conserva desde um certo tempo, com sua sistematicidade própria e num certo sentido independente da consciência dos homens" (FOUCAULT, 1996, p.30). Destarte, o discurso tem existência própria, sendo independente da existência desse ou daquele sujeito. Portanto, o pós-estruturalismo intensifica o combate à ideia de sujeito autônomo contido na modernidade, colocando em dúvida a visão de que existe uma "verdade" neutra e destituída de relações de poder, onde um determinado sujeito exerceria o papel profético de enxergá-la e de conscientizar os demais indivíduos, bem como rompendo com uma concepção de história contínua e linear, que sempre caminharia em direção ao progresso (FOUCAULT, 1979). Diante dessas primeiras observações, o que significa desejo para o pósestruturalismo?

Tanto Deleuze (1991) quanto Rolnik (1989) fazem uma forte crítica à concepção de desejo contida na teoria psicanalítica lacaniana e freudiana. Deleuze (1991), ironizando a obra de Lacan (1988) denominada de "Seminário 11: Os Quatros Conceitos Fundamentais da Psicanálise", escreve quatro proposições sobre a psicanálise. Estas proposições serão aqui apresentadas. A primeira proposição é que a psicanálise impede toda a produção de desejo, pois é inseparável de um perigo político e que se diferencia dos perigos contidos na velha concepção de hospital psiquiátrico. Enquanto o hospital psiquiátrico é um local fechado de internamento localizado, a psicanálise, contrariamente, funciona ao ar livre constituindo-se como uma grande empresa psicanalítica. Para Deleuze (1991), a psicanálise fala muito de inconsciente, contudo para sempre reduzi-lo ou destruí-lo, concebendo-o como se fosse uma contraconsciência, um parasita da consciência. 
O que a psicanálise chama de produção ou formação do inconsciente são sempre malogros, conflitos imbecis, compromissos débeis ou grandes jogos de palavras. Uma vez, entretanto, que isso dá certo, há de ser sublimação, dessexualização, pensamento, mas nunca desejo - o inimigo que se aninha no coração do inconsciente. Desejos, os há muito: perverso polimorfo. Ensinar-lhes-ão a Falta, a Cultura e a Lei, quer dizer, a redução e a abolição do desejo (DELEUZE, 1991, p. 198-199).

Para exemplificar a citação acima, Deleuze (1991) faz uma crítica da necessidade da existência de um objeto enquanto desejo para Freud. Assim, a psicanálise freudiana afirma que o objeto pênis pode ser substituído, interpretado e representado em uma teta de vaca, e a teta de vaca pode substituir o seio materno. Portanto, o objeto existe somente quando não se tem o mesmo em alcance. Sendo assim, para a psicanálise o objeto nunca é o verdadeiro desejo, mas sempre significa outra coisa, esconde outra coisa e esconde outro desejo. Isso acontece para Deleuze (1991) exatamente porque a psicanálise tem uma tabela perfeita onde

[...] os verdadeiros conteúdos de desejo seriam as pulsões parciais infantis; a verdadeira expressão de desejo seria Édipo (para estruturar 'o todo'). Logo que o desejo ajusta alguma coisa em relação com o Exterior e um Devenir, o ajustamento é desfeito e quebrado e, por um lado, vai-se mostrar que o desejo se dirige para um mecanismo parcial da criança, e, por outro, para uma estrutura global de Édipo (DELEUZE, 1991, p. 199).

Deleuze (1991) enxerga que nós nunca temos o inconsciente, pois o inconsciente é algo que deve ser produzido. O inconsciente é substância por fabricar, por movimentar, por situar, ou seja, um espaço político e social para conquistar. $\mathrm{O}$ inconsciente é revolução social que não tem nenhuma relação com atos falhos, pois não é um sujeito que produziria efeitos na consciência. Desta forma, para Deleuze (1991) o inconsciente é objeto de produção, pois é ele que deve ser produzido. Em outras palavras não existe sujeito de desejo, o desejo não é algo estático e produzido por uma estrutura pré-determinada. O desejo "é o sistema de signos assignificantes, a partir dos quais fluxos de inconsciente são produzidos no campo social histórico" (DELEUZE, 1991, p. 200). Todo desejo faz tremer nas bases o aparelho de Estado e põe em questão o campo social, pois o desejo é revolucionário porque sempre quer estabelecer mais conexões, sendo que a psicanálise corta e afasta todas as possibilidades de conexões. Rolnik (1989) concorda com a posição de Deleuze (1991) e afirma que o desejo não é caos, mas a falta de possibilidades de se estabelecer conexões e não os seus movimentos que o configuram como caos. O desejo é visto como o contrário de caos, pois o funcionamento do desejo é uma forma incansável de se fabricar mundos.

A segunda proposição de Deleuze (1991) refere-se à maneira como a psicanálise impede a formação de enunciados. Os fluxos do desejo ficam sujeitos na psicanálise à dominação de um sistema imperialista significante, sendo acuados para um mundo que o limita a uma representação mental onde suas intensidades são oprimidas e suas conexões desfeitas. "A psicanálise é feita inteiramente para impedir as pessoas de falarem e lhes retirar todas as condições de enunciação verdadeira" (DELEUZE, 1991, p. 202). Em outras palavras Deleuze (1991, p, 202) afirma que a

[...] psicanálise procede do seguinte modo: parte de enunciados coletivos, já feitos, do tipo Édipo, e tenta descobrir a causa destes enunciados num sujeito pessoal de enunciação que tudo deve à psicanálise. Desde o início, já se está preso à armadilha. Seria preciso fazer o contrário disso, [...].

A psicanálise procede para obter efeito de esmagamento do enunciado, para, assim, destruir o desejo. Esta é a terceira proposição de Deleuze (1991). O autor afirma que a psicanálise possui uma máquina dupla: primeiramente uma máquina de interpretação, que proporciona que tudo o que um paciente diga esteja previamente traduzido em outra linguagem, na qual tudo o que fala é admitido como querendo falar outra 
coisa. Assim, a psicanálise constitui-se como um regime paranoico, onde cada signo é remetido a outro, em uma rede ilimitada que está em perpétua expansão. "O signo, constituído como significante remete ao significado que, ele próprio, restitui significante" (DELEUZE, 1991, p. 203).

Além de ser uma máquina de interpretação, a psicanálise é uma máquina de subjetivação. Como máquina de subjetivação, a psicanálise faz com que o significante não seja mais considerado com relação a um significado qualquer, mas sempre com relação a um sujeito. "O ponto de significação tornou-se ponto de subjetivação: o próprio psicanalista" (DELEUZE, 1991, p. 204). Desta forma, para Deleuze (1991, p. 204)

São estas duas máquinas, uma na outra, que interrompem toda possibilidade de experimentação real, bem como impedem toda produção de desejo ou formação de enunciados. Interpretar e subjetivar são as duas doenças do mundo moderno que a psicanálise não inventou, mas para as quais encontrou a técnica de manutenção e propagação perfeitamente adequadas. Todo o código da psicanálise, as pulsões parciais, Édipo, a castração, etc. são feitos para isto.

A última proposição de Deleuze (1991) fala sobre as relações de poder estabelecidas pela psicanálise. Para o autor, a transferência não é um dos principais dispositivos de poder da psicanálise, mas sim a sua forma liberal-burguesa de contrato. No contrato estabelecido entre o psicanalista e o paciente "mesmo o silêncio do psicanalista representa o máximo de interpretação que passa pelo contrato e onde este culmina" (DELEUZE, 1991, p. 205). Entretanto, nesse contrato se desenrola um silêncio ainda maior que atua como um dispositivo de poder altamente eficiente. Esse dispositivo é que vai converter o fluxo da libido do paciente, cambiá-lo por sonhos, palavras, fantasmas, etc. Para Deleuze (1991), é exatamente nesse cruzamento que se instala o poder do psicanalista e "como todo poder, ele tem por objeto tornar impotente a produção de desejos e a formação de enunciados, numa palavra, neutralizar a libido" (DELEUZE, 1991, p. 205).

Para Rolnik (1989) a produção do desejo é produção de realidade, sendo indissociável e ao mesmo tempo material, semiótica e social. Para a autora, o desejo é uma produção social responsável pela criação e desmanche de mundos. "Fomos entendendo que o desejo não corresponde a um suposto campo individual ou interindividual, o qual estaria numa relação de exterioridade ao campo social" (ROLNIK, 1989, p. 56). Em outras palavras, não existe sociedade que não seja constituída por investimentos de desejo em uma determinada direção, "com esta ou aquela estratégia e, reciprocamente, não existem investimentos de desejo que não sejam os próprios movimentos de atualização de um certo tipo de prática e discurso, ou seja, atualização de um certo tipo de sociedade" (ROLNIK, 1989, p. 58).

O que Rolnik (1989) quer afirmar é que não existe distinção entre o mundo social e o desejo. A psicanálise considera o desejo algo individual e que seria limitado, castrado, reprimido por valores e normas sociais. Assim, existiria uma oposição entre o desejo, que se manifesta no plano individual, e os valores e regras sociais, que representariam o plano coletivo. Sendo para Rolnik (1989) o desejo a própria produção do real social, não existe distinção entre o social e o desejo. Rolnik (1989) evidencia que, contrapondo-se as ideias psicanalíticas de Freud e Lacan, o desejo não funciona na base da repressão, mas

Ao contrário, esse modo de produção funciona na base da incitação do desejo, mas sob a condição de interceptar o acesso ao invisível, entulhar tudo de imagem até que o próprio criador fique soterrado e não possa mais se lançar. Portanto, se há aqui uma espécie de repressão, seu objeto seria a própria fonte do gesto criador; este vai ficando, por si só, cada vez mais enfraquecido e, em alguns casos extremos (ao que parece, não tão raros), não chega sequer a se esboçar (ROLNIK, 1989, p. 118). 
Assim, para o pós-estruturalismo, a concepção e conceito sobre o desejo seguem os preceitos descritos por Deleuze (1991) e Rolnik (1989). Neste sentido, desejo não é entendido como um produto de processos repressivos e nem como algo caótico. Desejo é revolução, é mudança social. Todo desejo é uma produção social e coletiva, não se caracterizando como algo binário, identitário, caótico, interno ou íntimo.

\section{A Expansão da Vida pelo Desejo}

Todo discurso é constituído e validado por relações de poder, conforme Foucault (2002) demonstrou ao denunciar a relação existente entre poder e saber. Para Foucault (1988), o poder se exerce por meio de dispositivos e, dentre os vários dispositivos existentes em nossa sociedade, o dispositivo da sexualidade, formado pelas relações de poder direcionadas ao desejo, ocupa um papel importante em sua obra. Para o autor, o dispositivo da sexualidade age

De alto a baixo, em suas decisões globais como em suas intervenções capilares, não importando os aparelhos ou instituições em que se apóie, agiria de maneira uniforme e maciça; funcionaria de acordo com as engrenagens simples e infinitamente reproduzidas da lei, da interdição e da censura: do Estado à família, do príncipe ao pai, do tribunal à quinquilharia das punições cotidianas, das instâncias da dominação social às estruturas constitutivas do próprio sujeito [...] (FOUCAULT, 1988, p. 82).

Para ele, a instauração de um conjunto de regras e normas que se apoiaram em instituições religiosas, médicas, pedagógicas e judiciárias vai cunhar a sexualidade em nossa sociedade. $\mathrm{O}$ próprio termo sexualidade só nasce no início do século XIX. O surgimento desse termo marca o desenvolvimento "de campos de conhecimentos diversos (que cobriram tanto os mecanismos biológicos da reprodução como as variantes individuais ou sociais do comportamento)" (FOUCAULT, 1984, p. 9).

É dentro desse dispositivo historicamente construído que Foucault (1988) analisa a produção do desejo. Para ele (1988, p. 80), quando se estuda a sexualidade, o que está em jogo é dirigir-se "menos para uma 'teoria' do que para uma 'analítica' do poder". Infere-se que a sexualidade é constituída por relações de poder que fazem parte de um "jogo da verdade" sobre o próprio desejo. Entretanto, não há uma verdade ou essência em relação ao desejo. O que existem são dispositivos que produzem todo um discurso que estabelece toda uma regra de conduta.

Assim, para Foucault (1988), a sociedade que se desenvolve no século XVIII, denominada por ele de burguesa, capitalista ou industrial, não teve uma recusa em conhecer o desejo, pelo contrário, instaurou todo um aparelho capaz de produzir discursos verdadeiros sobre o desejo. Não apenas falou muito sobre ele, como também forçou todo o mundo a falar dele, além de formular uma verdade sobre ele "como se suspeitasse nele um segredo capital. Como se tivesse necessidade dessa produção de verdade. Como se lhe fosse essencial que o sexo se inscrevesse não somente numa economia do prazer, mas, também, num regime ordenado de saber" (Foucault, 1988, p. 68).

Em função do expostos pode-se constatar que o dispositivo da sexualidade é para Foucault (1988) uma das principais formas de controle social. Conforme demonstrado, Foucault (1988) entende como dispositivo da sexualidade todos os modos hegemônicos, sejam eles discursivos e/ou extradiscursivos, que atuam de forma capilar, apoiando-se em diversos aparelhos e instituições, atuando de forma uniforme e maciça, seja por meio da lei, da interdição, da censura, bem como das relações constitutivas do próprio sujeito, tendo como principal intento construir uma "verdade" não só sobre a sexualidade, mas inclusive sobre o desejo e, consequentemente, toda a vida social. 
Assim, quando se estuda a sexualidade, está se analisando ao mesmo tempo aspectos econômicos, políticos, sociais, culturais, legais, científicos, dentre outros. Entretanto, não existe uma primazia do econômico, político, social, cultural, científico e legal sobre a sexualidade, nem vice-versa. Sendo assim, estudar gênero e sexualidade constitui-se como algo fundamental para se entender a produção do desejo pelas relações de poder de uma determinada época, o que permite um melhor entendimento das estratégias de poder locais. Entretanto, essa empreitada só faz sentido se traz consigo um intento expansor da vida. Desejo é revolução. É mudança social. O desejo é capaz de construir novos tipos de práticas e discursos, promovendo a renovação e atualização de uma sociedade (ROLNIK, 1989; DELEUZE, 1991). Assim, o desejo possui grande força catalisadora no processo de mudança social, força esta que supera o econômico como principal agente de tais mudanças.

Ao fazer um estudo sobre as relações entre desejo e subjetividade, Butler (1999) se posiciona contrária à ortodoxia psicanalítica lacaniana. Para a autora, ao naturalizar e constituir a primazia simbólica do Édipo e da castração, acaba-se criando uma estrutura metafísica, binária, natural e a-histórica que restringe os processos de subjetivação a relações de poder universais e transcendentes, afastando-se do imanente, ou seja, se constrói uma metanarrativa. Em conformidade com Butler (1999), Arán e Peixoto Júnior (2007) afirmam que a insistência da tradição psicanalítica em ignorar aspectos relacionados à multiplicidade e diferença, as contingências sócio-históricas dos processos de subjetivação e a singularidade retira todo o potencial subversivo da psicanálise moderna para provocar mudança.

Portanto, se para Parker (2005) a emancipação só pode ocorrer na busca da verdade e do progresso, acreditase nesse artigo que o importante no processo de expansão da vida não é a busca da verdade ou do progresso, mas sim a análise das relações de poder que ao mesmo tempo são produtoras de desejo e produzidas pelo desejo. Relações estas que envolvem concomitantemente dispositivos legais, institucionais, educacionais, sexuais, sociais, econômicos, políticos, culturais e geográficos que estão relacionados com os processos de subjetivação dos sujeitos no trabalho (ARÁN; PEIXOTO JÚNIOR, 2007). Entretanto, isso não significa uma reificação de uma estrutura universal que moldaria os trabalhadores sexuados. Conforme Foucault (2003) salienta, não existe um poder que atua somente pela repressão ou dominação, pelo contrário, a subjetividade é construída em processos heterogêneos de relações de poder que atuam de forma conjunta e imediata na construção do indivíduo.

Nesse sentido, estudar as relações de poder que envolvem o desejo no trabalho é estudar concomitantemente um sistema que inclui o sexo, mas que não está diretamente determinado por ele (SCOTT, 1990). Portanto, desejo, sexualidade e gênero não estão enraizados na biologia. Também não se pode afirmar que as desigualdades de gêneros estruturam o resto das desigualdades sociais, nem se acredita que os sistemas binários feministas marxistas fundamentados na divisão sexual do trabalho possam promover a emancipação dos trabalhadores (SCOTT, 1990).

As diferenças existentes nas questões emancipatórias defendidas pelo marxismo clássico e combatidas pelo pós-estruturalismo também se manifestam nas questões direcionadas ao desejo. Dessa forma, a crença no progresso, na existência de uma verdade absoluta e no binarismo-identitário moderno contido no marxismo clássico faz com que se conceba o desejo seguindo os mesmos ditames daquilo que pretende combater. Dessa maneira, conceber o desejo sob uma perspectiva psicanalítica freudiana e, principalmente, lacaniana, dificulta o movimento de expansão da vida e reforça todas as relações de poder que se intenta combater, (re)produzindo um círculo vicioso similar ao descrito por Crozier (1981) no estudo do fenômeno burocrático.

Independentemente das divergências sobre os conceitos de poder entre o estruturalismo Freudiano/Lacaniano e o pós-estruturalismo, vale ressaltar que, nesse círculo vicioso, a psicanálise moderna também acredita na existência de um desejo neutro e a-histórico, ou seja, um desejo constituído livre das relações de poder, concebendo o desejo como algo construído por uma estrutura universal, afastando desse processo de constituição o poder. Exatamente por conceber o desejo como algo universal, metafísico e a-histórico, a psicanálise moderna torna-se incapaz de construir processos que promovam a expansão da vida na 
contemporaneidade, onde o poder atuaria de forma muito mais positiva (construção de novos modos de vida) do que negativa (repressão de modos de vida).

Contrariamente à concepção psicanalítica moderna de desejo, o pós-estruturalismo define o desejo como algo social, não havendo distinção entre o social e o desejo (ROLNIK, 1989, DELEUZE, 1991). O pósestruturalismo não entende o desejo como algo íntimo e pessoal, nem como algo construído por processos de repressão ou castração. A produção do desejo atua de forma muito mais positiva do que negativa, sendo que é exatamente nessa produção que se estabelecem diversas relações de poder que não se direcionam somente à sexualidade, mas também estabelecem relações econômicas, sociais, políticas, dentre outras. Por isso, falar sobre desejo é algo tão proibido e coibido, pois problematizar o desejo é ao mesmo tempo ameaçar e desestabilizar modos hegemônicos de vida e de controle.

\section{Conclusões}

Para o estruturalismo, a "razão" é o agente capaz de provocar mudanças sociais que possam promover o progresso e a emancipação do homem. (TOURAINE, 1998). Contrário à ciência moderna, o pósestruturalismo não acredita em processos emancipatórios universais e totalizantes, colocando em cheque a crença de que a "razão" seja capaz de promover tais mudanças (SARUP, 1996). Por esse motivo, o pósestruturalismo prefere utilizar o termo "expansão da vida" ao invés de "emancipação". Contudo, se a "razão" não é capaz de promover a expansão da vida, para o pós-estruturalismo, uma questão emerge: qual agente seria capaz de expandir a vida? O desejo.

Contrapondo-se à concepção de desejo construída pela psicanálise moderna/estruturalista, onde o desejo deve fixar-se em um objeto por meio do processo de catexia, processo esse que promoveria a harmonia social e evitaria o conflito, o desejo concebido no pós-estruturalismo não é algo fixo, mas sim agente capaz de quebrar a harmonia social e provocar conflito. Assim, ao invés de tentar preservar a harmonia social, o pós-estruturalismo quer questionar essa pseudo harmonia por meio da análise das relações de poder que atuam na produção do desejo. Assim, o desejo deixa de ser visto como algo natural, biológico, íntimo e autônomo, mas passa a ser visto como social e, assim o sendo, um elemento capaz de destruir, construir e reconstruir mundos, capacidade essa denominada por Deleuze e Guattari (1976) de desterritorialização, territorialização e reterritorialização.

Devido a essa influência recebida da psicanálise moderna/estruturalista que estudiosos organizacionais (CHANLAT, 1996a, 1996b; DEJOURS, 1992, 2001, 2003), mesmo usando teorias psicanalíticas lacanianas e freudianas em seu intento de construir relações de trabalho mais justas e promover a emancipação do homem no trabalho, acabam deixando o desejo como algo secundário nesse processo. Ou seja, influenciados pela valorização da razão passam a enxergar o inconsciente, no qual o desejo é constituído para a psicanálise moderna, como significando o oposto de "razão" e significando caos. Se na modernidade somente a razão é capaz de promover a emancipação e o progresso, o desejo, que é algo inconsciente e, portanto, irracional para a psicanálise moderna, não pode ser o principal agente promotor da emancipação.

Ressalta-se que negar a importância de obras como de Chanlat e Dejours na problematização da construção de espaços organizacionais que possam promover a expansão da vida dos trabalhadores, é negar aspectos contingenciais e a construção histórica do homem, bem como suas lutas emancipatórias. Contudo, em uma sociedade pós-moderna, não considerar o desejo e suas formas de produção como um elemento primordial na análise dos processos relacionados ao poder é reforçar velhas concepções que não promovem mudanças sociais no mundo do trabalho. Nesse sentido, o desejo deve ser visto como uma categoria útil de análise histórica e elemento expansor da vida, similarmente ao que Scott (1990) faz em relação aos estudos de gênero. 
Conforme Rolnik (1989) relatou, não há sociedade que não seja constituída por investimentos de desejo em uma determinada direção. Todo desejo é atualização de determinadas práticas e discursos, que por si só acaba provocando a atualização de certo tipo de sociedade. O que Rolnik (1989) e Deleuze (1991) deixam claro é que o desejo é capaz de mudar o mundo social, mundo este ao qual o trabalho também pertence. Portanto, as concepções pós-estruturalistas sobre o desejo têm muito a contribuir com os estudos organizacionais que não seguem a hegemonia funcionalista, exatamente pelo seu potencial de criação de novas formas de relações sociais que possam construir sociedades que promovam a expansão da vida em espaços laborais, tendo o desejo como principal catalisador desse processo.

Enfim, acredita-se que a concepção de desejo contida no pós-estruturalismo de Rolnik (1989) e Deleuze (1991) é fundamental para uma revitalização das teorias organizacionais. Pois considerar o desejo como algo social e histórico, investido por diversas forças que tentam moldá-lo segundo relações hegemônicas de poder, torna-o um dos principais catalisadores de mudança e elemento revelador dos dispositivos de poder da sociedade contemporânea.

\section{Referências}

ALVESSON, M.; DEETZ, S. Teoria crítica e abordagens pós-modernas para estudos organizacionais. In: CLEGG, Stewart R.; HARDY, Cynthia; NORD, Walter R. Handbook de estudos organizacionais. V.1. São Paulo: Atlas, 1998.

ALVESSON, M., WILLMOTT, H. Making sense of management: a critical introduction. London: Sage, 1996.

ANDRADE, A. N. Avaliação genealógica. In: Menandro, P. R. M.; Trindade, Z. A.; Borloti, E. B. Pesquisa em Psicologia: recriando métodos. Vitória: UFES. Programa de Pós-Graduação em Psicologia: CAPES. PROIN, 1999.

ARÁN, M.; PEIXOTO JÚNIOR, C. A. Subversões do desejo: sobre gênero e subjetividade em Judith Butler. Cadernos PAGU, v. 28, janeiro-junho, p. 129-147, 2007.

ARAÚJO, I. L. Introdução à filosofia da ciência. Curitiba: Editora da UFPR, 1993.

BAUMAN, Z. O mal-estar da pós-modernidade. Rio de Janeiro: Jorge Zahar Editora, 1998.

BAUMAN, Z. Modernidade líquida. Rio de Janeiro: Jorge Zahar Editora, 2001.

BUTLER. J. Subjects of desire: Hegelian reflections on twentieth-century France. New York: Columbia University Press, 1999.

CHANLAT, J-F. O ser humano, um ser de desejo e de pulsões. In: CHANLAT, J-F. O individuo na organização: dimensões esquecidas. v. 3. 3. ed. São Paulo: Atlas, 1996a.

CHANLAT, J-F. O ser humano, um ser estrangeiro para o outro. In: CHANLAT, J-F. O individuo na organização: dimensões esquecidas. v. 3. 3. ed. São Paulo: Atlas, 1996b.

COOPER, R.; BURRELL, G. Modernismo, pós-modernismo e análise organizacional: uma introdução. In: CALDAS, M. P.; BERTERO, C. O. (Coords.). Teoria das Organizações. São Paulo: Atlas, 2007.

COSTA, C. L. O feminismo e o pós-modernismo/pós-estruturalismo: (in)determinações da identidade nas (entre)linhas do (com)texto. In: PEDRO, J. M; GROSSI, M. P. Masculino, feminino, plural: gênero na interdisciplinaridade. Florianópolis: Editora Mulheres. 1998.

CROZIER, M. O fenômeno burocrático. Brasília: Editora Universidade de Brasília, 1981. 
DAVEL, E.; ALCADIPANI, R. Estudos críticos em administração: a produção científica brasileira nos anos 1990.

Revista de Administração de Empresas, v. 43, n.4, p. 623-647, out/dez., 2003.

DEJOURS, C. A loucura do trabalho: estudo de psicopatologia do trabalho. São Paulo: Cortez: Obore, 1992.

DEJOURS, C. A banalização da injustiça social. Rio de Janeiro: Ed. Da FGV, 2001

DEJOURS, C. O fator humano. Rio de Janeiro: Ed. da FGV, 2003.

DELEUZE, G; GUATTARI, F. O anti-édipo: capitalismo e esquizofrenia. Rio de Janeiro: Imago Editora LTDA, 1976.

DELEUZE, G. Saúde e Loucura. São Paulo: Hucitec, 1991.

DERRIDA, J. Gramatologia. São Paulo, Perspectiva, 2004.

DOSSE, F. História do estruturalismo. Bauru: Edusc, 2007.

FOUCAULT, M. Microfísica do poder. Rio de Janeiro: Edições Graal, 1979.

FOUCAULT, M. História da sexualidade II: O uso dos prazeres. Rio de Janeiro: Edições Graal, 1984.

FOUCAULT, M. História da sexualidade III: O cuidado de si. Rio de Janeiro: Edições Graal, 1985.

FOUCAULT, M. História da sexualidade I: A vontade de saber. Rio de Janeiro: Edições Graal, 1988.

FOUCAULT, M. Entrevista com Michel Foucault, por Sérgio P. Rouanet e J. G. Merquior. In: FOUCAULT, M.; ROUANET, S. P.; MERQUIOR, J. G.; LECOURT, D.; ESCOBAR, C. H. O homem e o discurso: a arqueologia de Michel Foucault. Rio de Janeiro: Edições Tempo Brasileiro, 1996.

FOUCAULT, M. A arqueologia do saber. Rio de Janeiro: Forense Universitária, 2002.FOUCAULT, M. Estratégia, poder-saber. Rio de Janeiro: Forense Universitária, 2003.

FREUD, S. Edição standard brasileira das obras psicológicas completas de Sigmund Freud. Rio de Janeiro: Imago, 1974a.

FREUD. S. As transformações do instinto exemplificado no erotismo anal. In: Freud, S. Edição standard brasileira das obras psicológicas completas de Sigmund Freud. v. XVII. Rio de Janeiro: Imago, 1974b.

FREUD. S. Três ensaios sobre a teoria da sexualidade e outros trabalhos. In: Freud, S. Edição standard brasileira das obras psicológicas completas de Sigmund Freud. v. XVII. Rio de Janeiro: Imago, 1974c.

FREUD. S. A história do movimento psicanalítico e outros trabalhos. In: Freud, S. Edição standard brasileira das obras psicológicas completas de Sigmund Freud. v. XVII. Rio de Janeiro: Imago, 1974d.

HARVEY, D. Condição pós-moderna: uma pesquisa sobre as origens da mudança cultural. 12. ed. - São Paulo: Loyola, 2003.

HATCH, M. J. Organization theory: modern, symbolic and postmodern perspectives. Oxford: Oxford University Press, 1997.

HASSARD, J. Sociology and organization theory. New York: Cambridge University Press, 1993.

JAMESON, F. Postmodernism, or the cultural logic of late capitalism. London: Plutuo, 1985. 
KIRST, P. G. et al. Conhecimento e cartografia: tempestade de possíveis. In: FONSECA, T. M. G.; KIRST, P. G. Cartografias e Devires: a construção do presente. Porto Alegre: Editora da UFRGS, 2003.

LACAN, J.; MILAN, B.; MILLER, J. O seminário: livro 1, os escritos técnicos de Freud. Rio de Janeiro: Jorge Zahar editor, 1986.

LACAN, J.; MILLER, J. O seminário, livro 11: os quatro conceitos fundamentais da psicanálise. Rio de Janeiro: Jorge Zahar Editor, 1988.

LACAN, J. O seminário: livro 4 : a relação de objeto. Rio de Janeiro: Jorge Zahar editor, 1995.

LÉVI-STRAUSS. Antropologia estrutural. Rio de Janeiro: Tempo Brasileiro, 1967.

LYOTARD, J-F. O pós-moderno. Rio de Janeiro: José Olympio, 1986.

MONTEIRO, J. D. Pós-modernidade: método? Atitude diante da vida? Outra coisa? Primeira incursão. Anuário de Literatura. v. 3, p. 41-56, 1995.

PARKER, M. Critique in the name of what? Postmodernism and critical approaches to organization. Organization Studies. v. 16, n. 4, p. 553-564, 1995.

PARKER, M. Capitalism, subjectivity and ethics: debating labour process analysis. Organization Studies. v. 20, n. 1, p. 25-45, 1999.

PETERS, M. Pós-estruturalismo e filosofia da diferença: uma introdução. Belo Horizonte: Autêntica, 2000.

ROLNIK, S. Cartografia sentimental: transformações contemporâneas do desejo. São Paulo: Estação Liberdade, 1989.

SALES, L. S. Consistência do Édipo na psicanálise Lacaniana: símbolos zero para o desejo. Fractal Revista de Psicologia, 20, 01, 2008.

SARUP, M. Identity, culture and the postmodern world. Georgia: The University of Georgia Press, 1996.

SAWAIA, B. B. Identidade: uma ideologia separatista? In: SAWAIA, B. B. As artimanhas da exclusão: análise psicossocial e ética da desigualdade social. Petrópolis: Vozes, 2001.

SCOTT, J. Gênero: uma categoria útil de análise histórica. Educação e Realidade. Porto Alegre, v. 16, n. 2, p. 5-22, $\mathrm{jul} / \mathrm{dez}, 1990$.

SOUZA, E. M.; BIANCO, M. F.; GARCIA, A. Pesquisa pós-moderna: a fragmentação e o devir no campo organizacional. In: XXX Enanpad, 2006, Salvador. Trabalhos Apresentados. Bahia, 2006.

SOUZA, E. M. Pós-modernidade nos estudos organizacionais: equívocos, antagonismos e dilemas. Em: XXXIV ENANPAD, 2010, Rio de Janeiro. Trabalhos Apresentados, Rio de Janeiro, 2010.TOURAINE, A. Crítica da modernidade. Petrópolis: Vozes, 1998.

VIEIRA, M. M. F.; CALDAS, M. P. Teoria crítica e pós-modernismo: principais alternativas à hegemonia funcionalista. In: CALDAS, M. P.; BERTERO, C. O. (Coords.). Teoria das Organizações. São Paulo: Atlas, 2007.

WEBER, M. Economia e Sociedade: fundamentos da sociologia compreensiva. Brasília: Editora Universidade de Brasília, v. 2, 1999. 